\title{
Inhibitory Effect of Ultrasonic Waves on the Larval Settlement of the Barnacle, Balanus amphitrite in the Laboratory
}

\author{
Hitoshi KitamuRA \\ Faculty of Fisheries, Nagasaki University, Nagasaki 852, Japan \\ Kanjo TAKAHASHI \\ Research Laboratory, Kyushu Electric Power Co., Inc. Fukuoka 815, Japan \\ and \\ Daimori KANAMARU \\ Kyuden Sangyou Co., Fukuoka 813, Japan \\ (Received July 10, 1995)
}

\begin{abstract}
The effects of ultrasonic waves for survival and settlement of the barnacle, Balanus amphitrite, were investigated under laboratory condition. Among the three frequencies $(19.5,28$, and 50 $\mathrm{kHz}$ ) of ultrasonic waves tested, $19.5 \mathrm{kHz}$ was found to be the most effective in decreasing the survival rate of the barnacle nauplii. A 50\% reduction in cyprid settlement was achieved by a total irradiation of about $140 \mathrm{kPa} \cdot \mathrm{sec}$, defined as the product of acoustic pressure $(\mathrm{kPa})$ and irradiation time $(\mathrm{sec})$, whereas some $4,300 \mathrm{kPa} \cdot \mathrm{s}$ was necessary to reduce to $50 \%$ the survival rate of nauplii or cyprids.
\end{abstract}

Fouling organisms, such as barnacles, mussels, bryozoans and algae, are responsible for many economical problems, including increase in fluid frictional resistance and corrosion of ship's hulls, cooling water systems for power plants, and aquaculture facilities. Although antifouling agents, for example, organotin are available, their use is limited owing to their toxicity to fish, shellfish and other organisms. Hence, more environmentally friendly antifouling systems are required to combat this problem.

The use of irradiation of ultrasonic wave is found to be an effective antifouling method. Earlier laboratory studies on the mortality effects on the larvae of fouling animals, such as barnacles and mussels, demonstrated the effectiveness of ultrasonic wave irradiation at frequencies of several tens of $\mathrm{kHz}$ (MORI et al., 1969; SuZuKI and KonNo, 1970). However, there are no reports available on its effects on barnacle settlement. Hence, investigations were undertaken to study: (1) the effect of ultrasonic wave on the survival of laboratory reared Balanus amphitrite nauplii, at three frequencies $(19.5,28.0$, and 50.0

Key words: ultrasonic waves, settlement inhibition, Balanus amphitrite
$\mathrm{kHz}$ ); (2) more detailed effects on both nauplii and cyprids at $19.5 \mathrm{kHz}$; and (3) the effect on larval settlement at $19.5 \mathrm{kHz}$.

\section{Materials and Methods}

\section{Irradiation instruments}

An acrylic acid resin tank $(30 \mathrm{~cm} \times 25 \mathrm{~cm} \times 120 \mathrm{~cm}$ high, with the seawater level at $100 \mathrm{~cm}$ ) was used for the exposure experiments (Fig. 1). An ultrasonic transducer (total area $195 \mathrm{~cm}^{2}$ ) was set at the bottom. A sonicpressure sensor (Kaijou Denki Co.) was also immersed in the water column. Waterfilled, $10 \mathrm{ml}$ capped glass tubes, each containing twenty laboratory-reared $B$. amphitrite nauplii (IIVI stage) or cyprids, were set in the tank at various distances $(1-100 \mathrm{~cm})$ from the transducer.

Larval culture

Nauplii, obtained from adult barnacles cultured with Artemia salina, were fed with the diatom Chaetoceros gracilis at $25^{\circ} \mathrm{C}$. Larval density was lower than two individuals $/ \mathrm{ml}$. More than $70 \%$ of the reared nauplii reached the cyprid stage in five days. Newly-transformed cyprids were collected and used on the following day for settlement assay. 


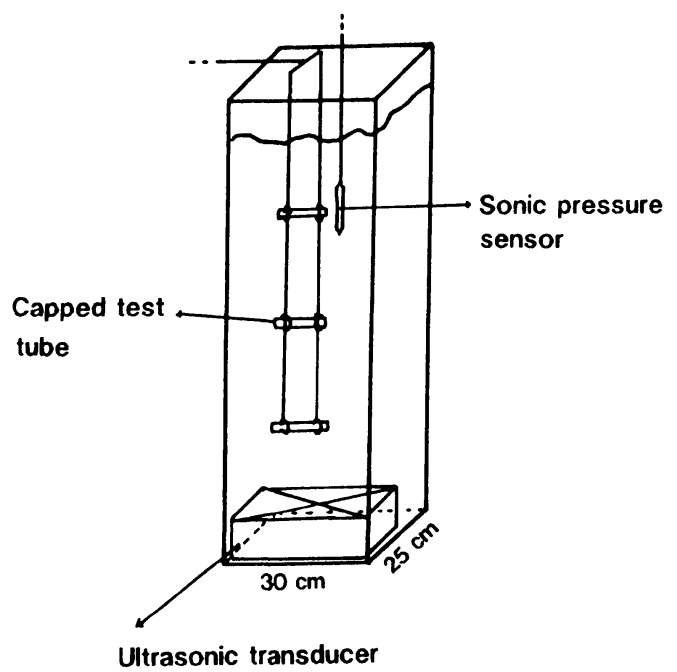

Fig. 1. Diagrammatic view of the radiation tank.

\section{Survival assay}

The effects on the survival of nauplii were investigated initially at three frequencies $(19.5,28.0$, and $50.0 \mathrm{kHz})$ for diverse exposure times $(5,10,20$, $30,40,50,60,70,80$, and $90 \mathrm{sec})$, at constant power $\left(240 \mathrm{~W}, 1.3 \mathrm{~W} / \mathrm{cm}^{2}\right)$ and distance $(1 \mathrm{~cm})$ from the transducer. For each experiment, three to ten glass tubes containing twenty larvae were used.

The effects of $19.5 \mathrm{kHz}$, the most effective frequency in killing the nauplii, on both nauplii and cyprids survival were investigated in detail to understand its impact of total irradiation $(\mathrm{kPa} \cdot \mathrm{s})$ on the survival rate of the larvae. Total irradiation is defined as the product of the acoustic pressure $(\mathrm{kPa})$ and the irradiation time (sec). Each test tube containing twenty nauplii or cyprids was irradiated with $19.5 \mathrm{kHz}$ ultrasonic wave for various times ranging from $5-120 \mathrm{sec}$ and distances between test tubes and the transducer $(1-100 \mathrm{~cm})$, at constant power $\left(1.3 \mathrm{~W} / \mathrm{cm}^{2}\right)$. Acoustic pressures on each test tube were detected by a sonic pressure sensor. Five to 32 capped glass tubes were used in each experiment.

\section{Settlement assay}

After treatment with $19.5 \mathrm{kHz}$ ultrasonic wave irradiation, the settlement activity of $B$. amphitrite cyprids was examined by settlement assay (KITAMURA and NAKASHIMA, 1993). The cyprids were placed into a $3 l$ capacity, plankton-net (opening; 96 $\mu \mathrm{m})$ cage, which was set up in a 15-l glass-tank containg $10 l$ of filtered seawater. Water circulation was maintained by a pump directing seawater to each

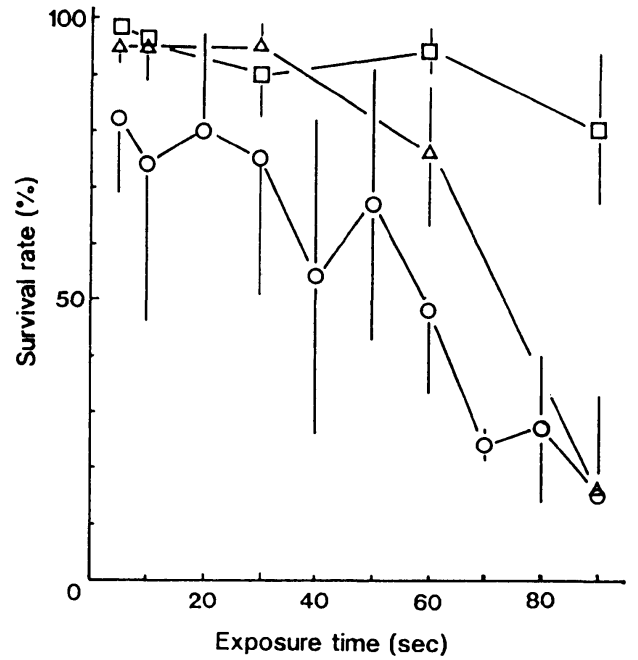

Fig. 2. Changes in the survival rate of Balanus amphitrite nauplii, exposured to ultrasonic waves at three frequencies, $19.5(\bigcirc), 28(\triangle)$, and 50 $\mathrm{kHz}(\square)$ at $1.3 \mathrm{~W} / \mathrm{cm}^{2}$ power, distance $1-2 \mathrm{~cm}$. Error bars denote standard deviation.

corner of the cage. For each experiment, 12 ceramics plates $(76 \times 26 \mathrm{~mm})$ were provided as substrata for settlement, of which six plates were pretreated (each plate coated with $1 \mathrm{ml}$ of crude extract of adult $B$. amphitrite equivalent to about $10 \mathrm{~g}$ wet-weight) and allowed to air-dry. The remaining plates were not treated. After $24 \mathrm{~h}$ at $25^{\circ} \mathrm{C}$, the number of individuals permanently settled on each plate was counted.

Settlement assays, each of two hundred cyprids (total of ten capped glass tubes), were subjected to total irradiations of 0 (control), 95, 125, 150, and $300 \mathrm{kPa} \cdot \mathrm{s}$. Exposure to $19.5 \mathrm{kHz}$ ultrasonic wave irradiation was at a distance of $100 \mathrm{~cm}$, under powers of $0.05-1.3 \mathrm{~W} / \mathrm{cm}^{2}$ (Table 1). Settlement assays were run with up to three replicates.

\section{Results}

\section{Survival assay}

The relationship between exposure time and survival rate of $B$. amphitrite nauplii at $19.5,28$, and 50 $\mathrm{kHz}$ (Fig. 2) showed the $19.5 \mathrm{kHz}$ ultrasonic wave to be the most effective in decreasing the survival rate. A gradual decrease in survival rates occured under $28 \mathrm{kHz}$ irradiation, whereas the $50 \mathrm{kHz}$ ultrasonic wave did not clearly reduce the survival rate of nauplii with increasing exposure time. The $19.5 \mathrm{kHz}$ 


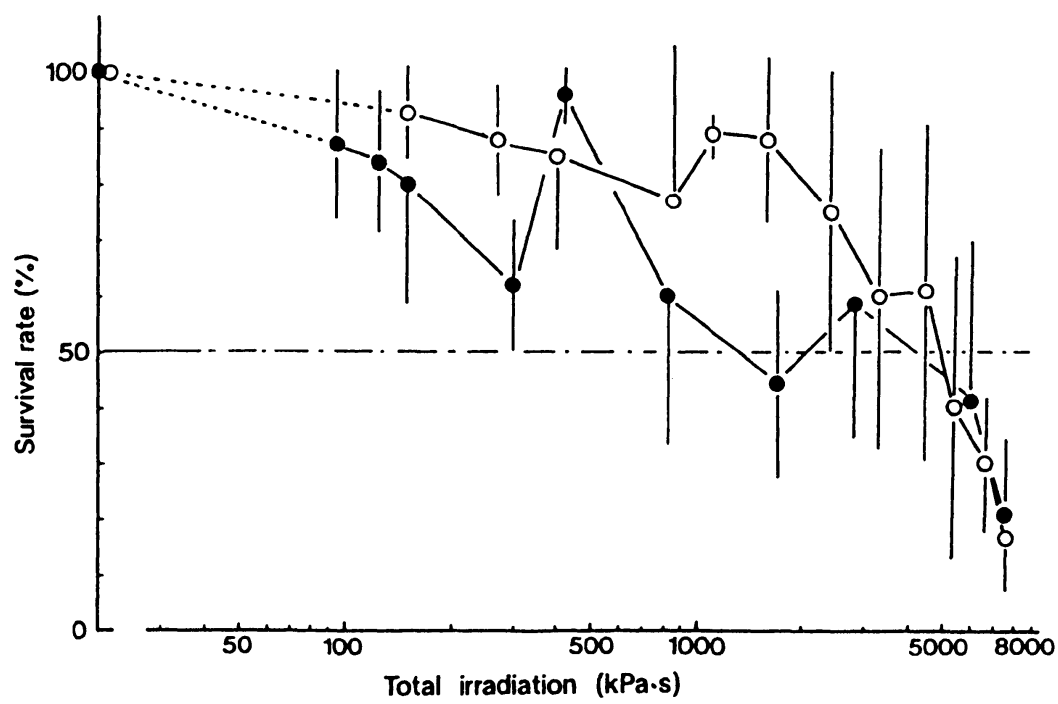

Fig. 3. Changes in the survival rate of Balanus amphitrite nauplii; $(\bigcirc)$, cyprids ( $)$ against total irradiation $(\mathrm{kPa} \cdot \mathrm{s})$. Error bars denote standard deviation.

Table 1. Number of settled barnacles after subjected to $19.5 \mathrm{kHz}$ at five levels of total irradiation (distance from transducer $100 \mathrm{~cm}$ )

\begin{tabular}{ccccccc}
\hline \hline \multirow{2}{*}{$\begin{array}{c}\text { Acoustic } \\
\text { pressure } \\
(\mathrm{kPa})\end{array}$} & $\begin{array}{c}\text { Irradiation } \\
\text { time } \\
(\mathrm{sec})\end{array}$ & $\begin{array}{c}\text { Total } \\
\text { irradiation*1 } \\
(\mathbf{k P a} \times \mathrm{sec})\end{array}$ & $\begin{array}{c}12 \text { plates } \\
(\text { total) }\end{array}$ & $\begin{array}{c}\text { Nreated } \\
\text { plates) }\end{array}$ & $\begin{array}{c}\text { (Untreated } \\
\text { plates) }\end{array}$ & $\begin{array}{c}\text { Number of } \\
\text { replicates }\end{array}$ \\
\hline $0^{* 2}$ & 0 & 0 & $62 \pm 22^{* 3}$ & $52 \pm 16$ & $10 \pm 9.6$ & 3 \\
19 & 5 & 95 & $53 \pm 1.4$ & $36 \pm 9.9$ & $17 \pm 8.5$ & 2 \\
25 & 5 & 125 & $51 \pm 13$ & $42 \pm 8.1$ & $9 \pm 5.5$ & 3 \\
30 & 5 & 150 & $24 \pm 13$ & $22 \pm 12$ & $2 \pm 1.0$ & 3 \\
30 & 10 & 300 & 18 & 16 & 2 & 1 \\
\hline
\end{tabular}

*1 Total irradiation $=($ acoustic pressure $) \times($ irradiation time $)$.

*2 Control.

*3 Standard deviation.

wave produced a linear decrease in the survival rate between 5 and $90 \mathrm{sec}$, with irradiation for $60 \mathrm{sec}$ reducing the survival rate to $50 \%$.

The relationships between total irradiation and the survival rate of nauplii and cyprids at $19.5 \mathrm{kHz}$ with diverse exposure times (5-120 sec) and distances (1$100 \mathrm{~cm}$ ) are shown in Fig. 3, the survival rates of both gradually decreasing with increasing total irradiation. Between 100 to $3,000 \mathrm{kPa} \cdot \mathrm{s}$, the survival rates of cyprids were lower than those of nauplii, but no clear differences in survival rates were apparent in the range 5,000 to $8,000 \mathrm{kPa} \cdot \mathrm{s}$. The levels of total irradiation which resulted in $50 \%$ survival rates of both nauplii and cyprids were almost the same, their values being calculated (method of DoudorofF et al., 1951) as 4,400 and 4,200 $\mathrm{kPa} \cdot \mathrm{s}$, respectively.

Settlement assay

The mean number of settled barnacles on $12 \mathrm{ce}-$ ramics plates was 62 in the control assays (without irradiation). The numbers on the pretreated and untreated plates being 52 and 10, respectively (Table 1). Exposure to the $19.5 \mathrm{kHz}$ ultrasonic wave progressively reduced the number of settled barnacles on the 12 plates, with increasing total irradiation from 95 to $300 \mathrm{kPa} \cdot \mathrm{s}$. At irradiation levels of 95 and 125 $\mathrm{kPa} \cdot \mathrm{s}$, the mean barnacle numbers on the 12 plates remained high, being 53 and 51, respectively, but decreased to less than $50 \%$ of the control number, 


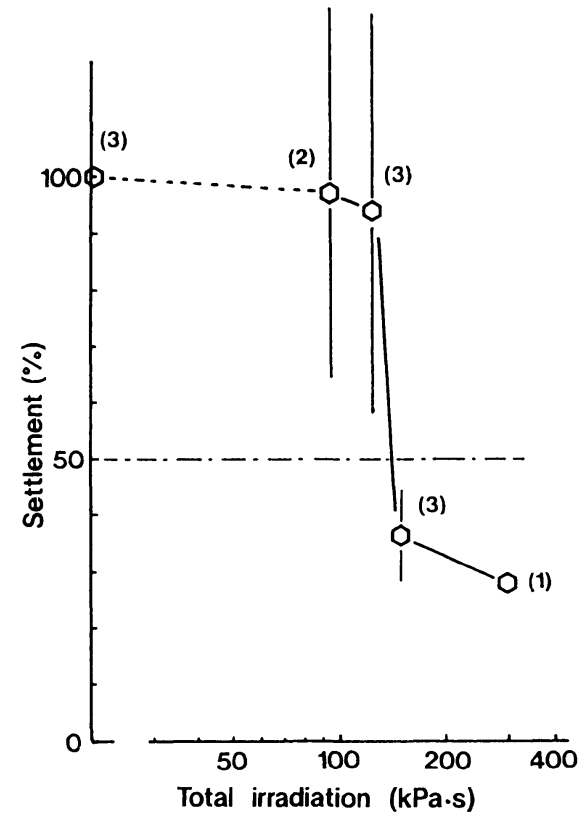

Fig. 4. Relationship between total irradiation $(\mathrm{kPa} \cdot \mathrm{s})$ of the $19.5 \mathrm{kHz}$ ultrasonic wave and settlement percentage of Balanus amphitrite cyprids (see text for explanation). Error bars and parentheses denote standard deviation and number of experiments, respectively.

under 150 and $300 \mathrm{kPa} \cdot \mathrm{s}$. The settlement numbers on treated plates remained higher than those on untreated plates throughout the experiments (Table 1). Almost all the cyprids exposed to ultrasonic waves swam normally, as did the control specimens.

The relationship between total irradiation and percentage of settled barnacles (Fig. 4), which was calculated on the basis of the barnacle numbers on the 12 control plates representing $100 \%$ settlement, indicated that the settlement percentage decreased sharply from $82 \%$ at $125 \mathrm{kPa} \cdot \mathrm{s}$ to $39 \%$ at $150 \mathrm{kPa}$. s. From the figure, irradiation of $140 \mathrm{kPa} \cdot \mathrm{s}$ achieved $50 \%$ inhibition on larval settlement.

\section{Discussion}

The results of the initial survival experiment using ultrasonic waves at three frequencies indicated that the $19.5 \mathrm{kHz}$ ultrasonic wave was the most effective in decreasing the survival rate of $B$. amphitrite nauplii (Fig. 2). The $28 \mathrm{kHz}$ wave, however, was also effective, but to a lesser extent, and the $50 \mathrm{kHz}$ wave not at all. The results obtained in the present investigation agreed with those of other studies (MORI et al., 1969; SUZuKI and KonNO, 1970).

It appeared that the lethal or destructive effect of ultrasonic waves on larvae was related to the total irradiation $(\mathrm{kPa} \cdot \mathrm{s})$. Although the survival rates of cyprids were lower than those of nauplii within the total irradiation range of 100 to $3,000 \mathrm{kPa} \cdot \mathrm{s}$, there was no difference in the survival rates from 5,000 to $8,000 \mathrm{kPa} \cdot \mathrm{s}$. The reason for the differing effects of the ultrasonic waves is not clear, but this may be related to the different shape of the two larval forms. The total irradiation levels which resulted in 50\% survival rates of both nauplii and cyprids were almost the same, being about $4,300 \mathrm{kPa} \cdot \mathrm{s}$.

The experimental inhibition of larval settlement by the $19.5 \mathrm{kHz}$ wave indicated that a total irradiation of $300 \mathrm{kPa} \cdot \mathrm{s}$ reduced barnacle numbers to about $30 \%$ compared to the control, whereas $125 \mathrm{kPa} \cdot \mathrm{s}$ reduced numbers to only about $80 \%$ (Fig. 4). In order to reduce the settlement of cyprids by half, total irradiation of about $140 \mathrm{kPa} \cdot \mathrm{s}$ is necessary. The barnacle numbers on treated and untreated plates (Table 1) indicated that cyprids subjected to ultrasonic waves retained the ability to select the pretreated plates, in the same manner as the control specimens. Throughout the experiments, the great majority of the exposed cyprids swam normally, evidence that the $19.5 \mathrm{kHz}$ ultrasonic wave injured neither the organs related to settlement, nor those necessary for swimming. Although the settlement abilities of the cyprid larvae were affected, microscopic examination of individual specimens failed to show the details.

On the present study, a total irradiation of about $4,300 \mathrm{kPa} \cdot \mathrm{s}$ was required to reduce the survival rate of larvae to $50 \%$, however, a considerably lower level of $140 \mathrm{kPa} \cdot \mathrm{s}$ also achieved $50 \%$ inhibition of larval settlement. The use of ultrasonic waves is considered to have the disadvantage of high energy consumption (FISCHER et al., 1984), but it is clear that much lower energy levels can be used to inhibit barnacle settlement under natural conditions. Consequently, the use of ultrasonic waves, at low energy levels as an antifouling tool, may well resolve the existing environmental problems of antifouling.

\section{References}

Doudoroff, P., B. G. ANDerson, G. E. Burdick, P. S. Galtsoff, W. B. Hart, R. Patrick, E. R. Strong, E. W. Surber, and W. M. VAN Horn (1951). Bioassay methods for the evaluation of acute toxicity 
of industrial wastes to fish. Sewage and Industrial Wastes, 23, 1380-1397.

Fischer, E. C., V. J. Castelit, S. D. Rodgers and H. R. BLEILE (1984). Technology for control of marine biofouling-a review. In: Marine Biodeterioration: An Interdisciplinary Study. (ed. by J. D. CostLow and R. C. TIPPER), Naval Institute Press, Annapolis, Maryland, pp. 261-299.

Kitamura, H. and Y. Nakashima (1993). Crude extracts of settlement factors from the barnacle Balanus amphitrite. OEBALIA, xix, Suppl., 609-612.

Mori, E., T. YAMAGUChI, Y. SAKAE and A. NishiKawA (1969). The anti-fouling effect of ultrasonic waves on hulls. Mitsubishi Heavy Industries TECHNICAL $R E V I E W, 6,1-9$ (in Japanese).

SuzuKI, H. and K. Konno (1970). Basic studies on the antifouling by ultrasonic waves for ship's bottom fouling organisms. J. Tokyo Univ. Fish., 56, 31-48 (in Japanese). 